\title{
English for University Administrative Work: English Officialization Policy and Foreign Language Learning Motivation
}

\author{
Jeongyeon $\mathrm{Kim}^{1} \&$ Jinsook Choi ${ }^{1}$ \\ ${ }^{1}$ Division of General Studies, Ulsan National Institute of Science and Technology, Ulsan, Korea \\ Correspondence: Jeongyeon Kim, Division of General Studies, Ulsan National Institute of Science and \\ Technology, 50 UNIST-Gil, Ulsan 689-798, Korea. Tel: 82-52-217-2013. E-mail: jkim@unist.ac.kr
}

Received: May 20, 2014 Accepted: July 15, 2014 Online Published: August 14, 2014

doi:10.5539/elt.v7n9p1 URL: http://dx.doi.org/10.5539/elt.v7n9p1

\begin{abstract}
This study examines how the English officialization policy of higher education in an EFL context interplays with administrative workers' motivational orientations towards English learning. The data consisted of questionnaire responses of 117 administrative members with undergraduate degrees and qualitative interviews with 9 who answered the questionnaires. The descriptive and correlation analyses showed that the participants interested in learning English-speaking countries' cultures did not perceive much benefit of the English officialization policy (EOP) in increasing their motivation to learn English. On the contrary, those who appreciated the EOP tended to be motivated to learn English for external rewards. A striking finding was that those who related the EOP to increased motivation also showed a lack of motivation to learn English. Also noteworthy was that their motivation correlated significantly with their own perceived English speaking competence. The results corroborate the significant role of the perception of English speaking competence and the context of English use in language learning motivation at the post-tertiary level. The participants expressed feelings of confusion regarding the role of English in everyday work performance. The implications of these findings are discussed with a view toward the enhanced implementation of EOP policy in an EFL context.
\end{abstract}

Keywords: English for workplace, English officialization policy, L2 motivation, perceived speaking proficiency, university administrative workers

\section{Introduction}

For the past decade, in the midst of this increasingly interdependent and globalized world, Korean society has faced domestic and international competition. As a phenomenon in the 21 st century, globalization, as seen in the present day, is shaped by various social changes, such as "an increasingly integrated world economy, new information and communications technology, the emergence of an international knowledge network, and the role of the English language, and other forces beyond the control of academic institutions" (Altbach, Reisberg, \& Rumbley, 2009, p. 7). Since this major social change has profoundly affected higher education institutions (HEIs), Korean HEIs have responded to globalization and adopted a variety of strategies and policies to internationalize campuses. One of the major strategies is to expand the role of English campus-wide and shift English from a major foreign language to an official language. Apparently, this enforcement of English is mainly due to the role of English as the medium of international communication in various social sectors such as business, technology, science, and even the Internet (Crystal, 2000, 2008; Graddol, 1997; Swales, 1987). The strategy to officialize English has been enforced not only in education, but also in research and administration of HEIs in Korea.

For the task of the internationalization of education, Korean universities, like those in many Asian countries, have adopted English-medium instruction (EMI). As of 2011, about $30 \%$ of the classes in some of the leading universities in Korea have been offered in EMI (Aju University, 2012). While second language (L2) researchers have reported positive and negative aspects of EMI (e.g., Chang, 2010; Cho, 2012; Jensen \& Johannesson, 1995; Kahng, 1999; Manakul, 2007; Manh, 2012; Rivers, 2011; Tsuneyoshi, 2005), one Korean university, the research site of the current study, launched a foreign language policy which has expanded the English officilization policy (EOP) to administrative work. The EOP includes not only the official use of English in administrative acts, but also an additional foreign language assessment used to measure work performances. That is, a certain level of English competence is a prerequisite for the workers to fulfill their work responsibilities and 
to be eligible for promotions.

Changes in the work environment due to the EOP should affect the workers' orientations to develop and improve their English competence, i.e., foreign language motivation. As suggested by many L2 researchers, L2 motivation, a major learner factor, is signifiantly influenced by social and contextual factors (Dörnyei, 2001; Ghenghesh, 2010; Long, Ming, \& Chen, 2013; Kim, 2010; Kormos, Kiddle, \& Csizér, 2011; Noels, Pelletier, \& Vallerand, 2000; Vandergrift, 2005; Zhao, 2012). Regarding the close interaction between an external context and L2 learners' internal responses to the context, Deci and Ryan $(1985,1995)$ proposed self-determination theory which explicates two main motivational orientations: intrinsic and extrinsic ones. L2 learners may be intrinsically motivated to learn a language for their own enjoyment. Learners may also be extrinsically motivated to learn a language because of some potential rewards that can be gained by developing language competence. L2 researchers have applied this self-determination theory to different contexts under a variety of social influences and have revealed that an L2 learner's response to the context forms a certain motivational orientation, which is significantly related with learner autonomy (Dörnyei, 2001; Ghenghesh, 2010; Long, Ming, \& Chen, 2013; Kormos, Kiddle, \& Csizér, 2011; Noels et al., 2000; Vandergrift, 2005).

In this study, we explore the relationship between L2 motivation at the post-tertiary level and the contextual factor of the EOP in a workplace. We address the dynamics of motivation in relation to this foreign language policy in a Korean university as a workplace. The following three research questions were developed to investigate the overarching topic of how university administrative members' perceptions of the EOP are interrelated with their motivational orientations to learn English.

1) How do administrative workers of a Korean university perceive the workplace context defined as the EOP?

2) In what ways are their perceptions of the EOP interrelated with the L2 motivational orientations?

3) How are the perceptions of the EOP and the motivational orientations interrelated with their perceived English speaking proficiency?

Since this new policy has recently attracted policy-makers from an increasing number of HEIs in countries where English is used as a foreign language, the findings of this study will contribute to understanding how a foreign language policy interacts with employees' language learning motivation in practice. The findings will also help L2 practitioners understand how to facilitate more effectively L2 learners' academic socialization and create a supportive educational community at the post-tertiary level.

\section{Review of Literature}

\subsection{English Officialization Policy and English in a Workplace}

The current trend of the EOP at HEIs represents the spread of English starting in the 1990's (Block, 2004). Given the vast extent of English use on a global scale, many business and academic sectors have approached English training in terms of the skills necessary for their own work performances. In response to this practical need, L2 researchers and educators have proposed English for specific purposes (ESP), such as English uses for business, Engineering and for diverse workplaces (e.g., Evans, 2011; Johns \& Dudley-Evans, 1991; Johns \& Price-Machado, 2001). Evans (2011) examined patterns of language choice in a professional workplace in Hong Kong, where English is officially enforced. Whereas English functioned as a major medium of written communication, Cantonese was dominant for oral interactions. The participants also showed more confidence in writing than in speaking. A need analysis of the target learner group has been proposed as a necessary condition for ESP curriculums to be properly implemented (e.g., Edwards, 2000; Ockey, 2014).

Studies on English language use in Korean workplaces have provided critical information on the skills that are necessary for Korean business and industry to be competitive (e.g., Cho et al., 1998; Choi, 2002; Park \& Jung, 2006). According to Choi (2002), employees in the product distribution department used English skills most often, whereas those in production teams rarely had a chance to use any English at all. Park and Jung (2006) examined the use of English at a workplace in terms of the test of English proficiency at the time of employment, the amount of time spent learning English during the employment term, and the amount of English skills required at work. The findings revealed disparity between the participants' perceptions of required English competency and the uses of English in reality, as only one-third of the participants engaged in a work which needed English reading skills. The results indicated that the participants' willingness to improve their English competency strongly correlated with their perception of English as conferring potential economic or social advantages rather than with the real demands associated in workplace. 


\subsection{L2 Motivation}

L2 motivation has drawn much attention from researchers who tried to investigate dynamic relations between motivation and other factors. The early, pioneering study on motivation by Gardner (1985) defined motivation as the desires and stimuli of learners. He classified motivation into two aspects, integrative and instrumental motivation. Based on this model, the concept of motivation has been refined for decades and applied in various pedagogical researches, such as the role of the motivation or its effects on language proficiency (e.g., Deci \& Ryan, 1985, 1995; Dörnyei, 1990; Kachru, 1992; Noels et al., 2000; Vallerand, 1997; Vallerand et al., 1992, 1993; Vandergrift, 2003, 2005). Specific subscales of motivation have been developed in relation to learner autonomy, namely the self-determination theory, in which learners' orientations to motivation are classified into three different categories: amotivation, extrinsic motivation, and intrinsic motivation (Deci \& Ryan, 1985, 1995; Noels et al., 2000; Vandergrift, 2005). Learners may see no relation between their actions and the consequences of those actions, i.e., the state of amotivation. As learners pursue an instrumental goal, extrinsic motivation is manifested. This second category of motivation can be divided into three subtypes, which again indicate the extent to which learners are autonomous, or self-determined: external regulation, introjected regulation, and identified regulation. On the other extreme, learners may have intrinsic motivation as they participate in learning for their own enjoyment and satisfaction. Crucial in this classification is that these three categories represent the extent to which a learner is autonomous while participating in specific learning activities. The categories are thus lying on a continuum, rather than being separate from each other.

Empirical research on L2 learning has supported the classification of motivational orientations as they have been associated with differences in L2 outcome (Noels et al., 2000; Vallerand et al., 1992, 1993; Vandergrift, 2003, 2005). Noels and her colleagues (2000), in their quantitative study of L2 motivation, showed that learners' perceived English competence and freedom of choice in learning the language are clear indicators of which subscale of motivation is manifested in a certain condition. Those who perceived their English competence lower than their peers without sufficient freedom of choice in the learning process tended to be amotivated to learn the language. It was suggested that in order to foster sustained learning, it may not be sufficient to convince students that language learning is interesting and enjoyable; they may need to be persuaded that it is also personally important for them. Vandergrift (2005) supports the close relationship between learner autonomy and motivation, and indicates that the self-determined and motivated learners, i.e., adolescent learners of French, are likely to invest more time and effort required for self-regulatory learning and to use metacognitive listening strategies. Therefore, language programs need to emphasize learner autonomy, which will in turn foster students' motivation and potential success (Littlewood, 1996, 1999; Noels et al., 2000; Vandergrift, 2005).

The effect of context on motivation has been found especially significant, as the context is in dynamic interaction with L2 learners' motivation and learning outcome (Kormos, Kiddle, \& Csizér, 2011; Kozaki \& Ross, 2011; Vandergrift, 2003, 2005; Zhao, 2012). In a learning context, the factors are frequently addressed as external factors which include teachers, activities, feedback, and classroom environment (Zhao, 2012). Among the external factors, the role of the teacher was found particularly significant in forming students' motivation to learn L2 (Ghenghesh, 2010; Long, Ming, \& Chen, 2013). Interestingly, teachers tended to perceive their students' L2 learning motivation to be intrinsic and integrative while their students brought more of instrumental and intrinsic motivation to the L2 classrooms (Zhao, 2012). To date, little is known about the relationship between the EOP as an external factor and L2 motivation at the post-tertiary level in a workplace. Thus, in this study, we aim to ameliorate the gap in research, and investigate this topic with a methodology that can handle the data not only quantitatively but also qualitatively. The results and the discussion of the analysis will follow the explanation of the methodology in the subsequent parts of this study.

\section{Methodology}

\subsection{Participants and the Context}

A total of 117 Korean administrative workers made up of 76 males and 41 females, working at a Korean university, participated in this study. The participants' ages ranged from 27 to 49 , with the vast of majority (91 participants) in their 30's and 40's. At the time of the research, they had worked for the same large research-oriented university located in a metropolitan city in South Korea for anything between six months and three years. Regarding levels of English proficiency, 85 respondents reported their TOEIC listening and reading scores. Among those, the scores of 78 respondents fell between 730 (limited working proficiency) and 850 (effective language use), while the other seven participants reported scores higher than 850, according to TOEIC rating scale. Only four respondents had lived in English speaking countries a year or more (1-3 years), while 19 respondents reported having done so for between 6 months and 12 months. Therefore, most of the respondents, 
94, had no experience or less than 6 months living in an English-speaking country.

The university launched its English as an official language policy in 2011. Since then, the medium of instruction has been English for all the official courses. In order to widen the scope of the policy to the administration, the institution organized a task-force team in 2011 for the full execution of the policy by 2015 . The complete execution of the policy included English use across the entire campus, including in education, official meetings, and administrative work. When the current research was conducted in fall, 2012, the EOP was in the first stage in which all the credit courses were offered in EMI, and all the official documents were produced and exchanged in English. As shown in the following table (Table 1), the university had a three-stage plan for the EOP.

Table 1. Stages of implementation of EOP

\begin{tabular}{lll}
\hline Stage & Goals & Category \\
\hline $1(2011-2)$ & EMI & Education \\
& English-written official documents & Administration \\
& English-written notices in campus & Administration/ \\
& & Students \\
$2(2013-4)$ & English communication & Administration \\
& English uses in official campus events/ & Administration/ \\
& Meetings & academic activities \\
& English-only dormitory (dormitory 1) & Students' living \\
$3(2015)$ & English-only campus & Administration/students \\
& (all campus/dormitory) & \\
\hline
\end{tabular}

The administrative workers were strongly encouraged to use English at work. All had completed English composition and speaking tests for employment administered by this university. Other than the drive to use English, the university included an English assessment score, as one of the criteria to be used to evaluate job performance. Therefore, the EOP, although not fully executed for the administrative workers at the time of research, had already begun to affect many aspects of their work.

\subsection{Procedure}

The study was conducted both in a quantitative and a qualitative manner. For the quantitative examination, a 22 items were included in the questionnaire. Following the first three items on participants' work, and English learning backgrounds, two items (items 4 and 5) asked the participants' perceptions of their own current English proficiency and critical English skills under the full execution of the EOP. They were asked to evaluate their English competence in terms of the communicative skill (item 4), and then to order the four language skills, i.e., listening, speaking, reading, and writing, in accordance with the significance of the skills in the English-only campus (item 5). Three items (items 6-8) addressed the main contextual factor of the EOP in terms of how much they related this policy to their current and future work conditions and motivation to learn English.

The items on motivation (items 9-22) were developed based on the Language Learning Orientations Scale used by many SLA researchers, including Noels et al. (2000), Vandergrift (2005) and Yang (2011). The items represented three different types of motivation: extrinsic motivation (items 9-14), intrinsic motivation (items 15-20), and amotivation (items 21 and 22). Extrinsic motivation was classified into three subscales: external regulation (items 9 and 10), introjected regulation (items 11 and 12) and identified regulation (items 13 and 14). The six items that followed represented another three subscales of intrinsic motivation: knowledge (items 15 and 16), accomplishment (items 17 and 18), and stimulation (items 19 and 20). The last two items (items 21 and 22) represented amotivation (See Appendix).

After collecting the data from questionnaires along with their consent forms, we interviewed nine participants for qualitative examination of the data. Each interview was conducted in Korean and lasted for 20-30 minutes. During the interview, they freely talked about their English learning experiences, work performances, and thoughts on the EOP. The audio-recorded interview data were transcribed and cross-examined for the study of their perception of the context and English-learning motivation. 


\subsection{Data Analysis}

The SPSS statistical program was used to process the quantitative data. The statistical analysis included descriptive statistics and correlation coefficients. The descriptive statistics calculated the participants' motivational modality, and their perception of contextual factors in terms of average scores. Correlation coefficients were employed to examine not only the interrelationship between motivation and contextual factors, but also the relationships among motivation, contextual factors, and perceived speaking proficiency.

Some researchers (e.g., Macintyre \& Legatto, 2011; Vandergrift, 2005) strongly recommend an interpretive component using methodologies such as in-depth interviews or case studies in addition to questionnaires in order to reveal influential factors, i.e., the reasons for students' responses on questionnaires. Therefore, this study included a qualitative analysis which aimed to gain some insights into the participants' views, beliefs and opinions on their context of English use.

\section{Results and Discussion}

\subsection{Perception of the Workplace Context}

In order to examine how the participants perceived the workplace context of the EOP, we calculated their responses to the questionnaire items. The reliability estimate for the EOP had a Cronbach's coefficient alpha value of 0.746 , which was considered acceptable in this study. The result, as presented in Table 2, indicated that the score on the EOP was slightly higher than the average, 3.14. The participants felt driven to learn English because of the EOP, or related the policy to their work only moderately.

Table 2. Perception of the context

\begin{tabular}{lll}
\hline Contextual factors (item number) & Mean & S.D. \\
\hline EOP (items 6-8) & 3.14 & .629 \\
\hline
\end{tabular}

In the qualitative interviews, the participants showed mixed responses to the policy. One interviewee's response explains this perception as shown in the following.

"Right now in our work, we are handling many English documents. Reading them is not so stressful, but sometimes I don't know why I have to read and write the documents in English, because I know I am sending the documents to my Korean coworkers in the main building. I understand that faculty members and students should communicate in English, because all the classes are taught in English. But it seems inefficient for us to do the work in English. We need to rewrite the documents in Korean if we are to communicate with other universities." (P-02)

As commented above, the participating administrative workers at the university tended to relate the policy to education, rather than administration, and indicated inefficient work performances due to the policy. For example, the EOP, they perceived, added to translation work for a communication with other universities.

\subsection{Relationship between Context and Motivation}

Some L2 researchers have indicated that an L2 motivational orientation interacts with social, context-specific factors, and, as a result, can be transformed into a different type of motivation (e.g. Iyengar \& Lepper, 1999; Littlewood, 1999; Murray, 2007; Vandergrift, 2005). Kormos, Kiddle, and Csizér (2011) claim that the influence of educational context and social environments on goals, self-related beliefs, and attitudes is mostly likely to be unidirectional as contexts including educational policies affect the workings of motivation in a learning process. In light of this proposal, this study examined the correlation coefficients between the contextual factors and the participants' motivational orientations.

We investigated the motivational dynamics in terms of three main types of motivation, i.e., extrinsic motivation (EM), intrinsic motivation (IM), and amotivation (AM). The reliability estimates for the EM, IM, and AM have been calculated. Cronbach's coefficient alpha values were 0.772 for EM, 0.826 for IM, 0.891 for AM, respectively, all of which were acceptable in this examination. As Table 3 shows, the participants were highly motivated to learn English under the EOP, but scored low on amotivation. They were found to be motivated to learn English both extrinsically and intrinsically, and their response scores marked higher than average, i.e., 3 . Between EM and IM, the EM score was higher than the IM score, which explains that the participants' orientation to external awards. Specifically, they were found to relate English speaking to personal development or enhancement of their qualities (Identified EM) or to pursue rewards in their majors or future jobs (External 
EM) rather than out of a sense of the global citizenship or to display the ability to speak English to friends or teachers (Introjected EM).

Among the three IM subscales, IM-Accomplishment scored the highest. That is, the participants were strongly motivated to learn English for the feelings of accomplishment from successful daily work performances in English (IM-Accomplishment). In the same line, interactions with English native speakers stimulated their English learning motivation (IM-Stimulation). By contrast, their motivation to acquire knowledge of western ways of thinking or living (IM-knowledge) was lower than average, i.e., 2.86.

Table 3. Motivational types

\begin{tabular}{lll}
\hline Motivational types (item number) & Mean & S.D. \\
\hline EM (items 9-14) & 3.71 & .715 \\
External EM (items 9 and 10) & 4.00 & .824 \\
Introjected EM (items 11 and 12) & 3.22 & 897 \\
Identified EM (items 13 and 14) & 4.10 & .888 \\
IM (items 15-20) & 3.20 & .931 \\
IM-Knowledge (items 15 and 16) & 2.86 & 1.156 \\
IM -Accomplishment (items 17and 18) & 3.45 & .999 \\
IM-Stimulation (items 19 and 20) & 3.30 & 1.081 \\
AM (items 21 and 22) & 1.99 & .982 \\
\hline
\end{tabular}

Correlation analysis showed that the EOP correlated with most of motivational constructs, as presented in Table 4. The EOP correlated with extrinsic motivation more significantly than with intrinsic motivation. They related the policy mostly to their orientation for external rewards, benefits or self-development. By contrast, as the significant negative correlation indicates, those who pursued his/her own personal development or an image of a fluent English speaker at the workplace (Identified EM) had a tendency to perceive the policy negatively in terms of its contribution to increasing their motivation to learn English.

Table 4. Correlation coefficients between motivation and EOP

\begin{tabular}{ll}
\hline Motivation/Contextual Factors & EOP \\
\hline EM in total & $.409^{* *}(.000)$ \\
External EM & $.293^{* *}(.001)$ \\
Introjected EM & $.375^{* *}(.000)$ \\
Identified EM & $-.378^{* *}(.000)$ \\
IM in total & $.202^{*}(.030)$ \\
IM-Knowledge & $.057(.544)$ \\
IM -Accomplishment & $.286^{* *}(.002)$ \\
IM-Stimulation & $.197^{*}(.034)$ \\
AM & $.346^{* *}(.000)$
\end{tabular}

**. Correlation is significant at the 0.01 level.

*. Correlation is significant at the 0.05 level.

One of the most striking findings in this correlation analysis is the significant positive relationship between the EOP and amotivation. This is interesting because both EM and IM correlated negatively with AM in the correlation an alysis $(\mathrm{p}<.01)$. However, as shown in Table 4, those who related the EOP to increased EM and IM motivations also showed a lack of motivation to learn English. In the follow-up qualitative interview, most of the interviewees commented on the confusion between the policy and work performance. 
“In college I was an English literature major. I enjoy learning about English-speaking countries' cultures, like their movies and dramas. Here (at the workplace), I feel like I'm forced to improve my English to be better in my work. But the thing is I could perform much better if it were not for the policy. I think I can be more efficient." (P-04)

"I think we all know that, in this environment, we should be trying to improve our English. But in my current position, I wouldn't be able to get promoted to a permanent position even if my TOEIC score was very high. So for what? I don't know why I should bother to invest my time to study English.” (P-03)

As mentioned above, it seems that the university's policy has driven the workers to learn and improve English, which, to most of the participants in this study, does not agree with other requirements, such as work efficiency and promotion opportunity. Their confusion due to this gap between the policy and the current work has engendered the contradictory results in the correlation between the policy and amotivation. Interestingly, they agreed that they were amotivated to learn English, because their efforts might not be rewarded in terms of work performance in general and the real promotions.

\subsection{Relationship among Context, Motivation, and Speaking Proficiency}

Given the motivational dynamics that are under the influence of the contextual factor of the EOP, this study investigated how these motivational and contextual constructs could be interrelated with English speaking proficiency as perceived by the participants. The participants were asked to rank the four English skills by the significance they believe the skills will have when the EOP has been fully executed (item 5). Most of the staff members perceived speaking as the most significant, necessary skill as the campus is supposed to be fully English-only (Table 5). Next to speaking, listening was marked second in significance. This is not surprising, as these two skills occur simultaneously in conversational encounters. A striking difference was found in their perception of reading and writing under the EOP. These two skills ranked the lowest in significance, which indicates that the participants hardly perceived them significant under the policy at all. This result is interesting because the EOP has mandated English documentation throughout the administration. Therefore, reading should remain very critical under the full execution of the policy. The participants, however, evaluated the importance of reading and speaking differently, as speaking was perceived to be much more important than reading.

Table 5. Rankings of English skills by significance under EOP*

\begin{tabular}{lllll}
\hline Ranking/Skills & Listening & Speaking & Reading & Writing \\
\hline 1 & $20(17.0)$ & $80(68.3)$ & $6(5.1)$ & $11(9.4)$ \\
2 & $50(42.7)$ & $24(20.5)$ & $11(9.4)$ & $32(27.3)$ \\
3 & $37(31.6)$ & $5(4.2)$ & $45(38.4)$ & $29(24.7)$ \\
4 & $10(8.5)$ & $8(6.8)$ & $55(47.0)$ & $45(38.4)$ \\
\hline
\end{tabular}

* The numbers represent frequency and its percentage within each skill, i.e., frequency (\%)

The interviewees commented on how they would react to the full execution of the policy in three years. According to them, as shown in the following extract, speaking is a more challenging skill than reading, and under the full execution of the policy, they feel that their work will include more speaking-related work.

"Reading is just reading. It can be time-consuming, but doesn't create an instant problem. But, speaking English almost all the time at work is a different story. Even now, if I have to pass on a short notice to a foreign faculty member, I just email him in English. I avoid speaking to him." (P-08)

The subsequent item, then, asked how the participants would evaluate their English speaking skill for communication. They chose one of the three options: 1) only beginner level reading and listening, difficulty with speaking; 2) ability to participate in a short English dialog, but difficulty with discussion or negotiation; and 3) minimal difficulty with English speaking. As shown in Table 6, respondents overwhelmingly chose the second option, i.e., ability to participate in a short English dialog, but difficulty with discussion or negotiation. The lowest speaking proficiency, i.e., only beginner level reading and listening, but difficulty with speaking, marked the second highest frequency, while the advanced level of proficiency marked the lowest frequency. Only $23 \%$ of the participants perceived themselves to be competent English speakers capable of managing English communicative tasks with little problem. 
Table 6. Perceived English speaking proficiency

\begin{tabular}{lll}
\hline Item 16 & Frequency & Percent \\
\hline 1) Beginner & 35 & 29.9 \\
2) Short dialog & 55 & 47.0 \\
3) Advanced speaking proficiency & 27 & 23.0 \\
\hline
\end{tabular}

The differences in perceived English speaking proficiency have then been cross-examined with the motivational and the contextual construct (EOP). First, in the examination of the relationship between motivational subscales and the participants' perceived speaking proficiency, IM was found to correlate with the perceived speaking proficiency more significantly than EM. The correlational pattern indicates that those highly extrinsically motivated to learn English for concrete rewards, such as promotion (External EM) or self-development (Identified EM), perceived their English speaking skill to be advanced. However, more importantly, the group of participants with higher intrinsic motivation, such as learning about English-speaking countries' culture (IM-Knowledge) or pursuing the feeling of achievement (IM-Accomplishment), showed even more confidence in their speaking proficiency (Table 7).

Table 7. Correlation coefficients between motivational subscales and perceived English speaking proficiency

\begin{tabular}{lll}
\hline Motivational types & Speaking proficiency & $\mathrm{P}$ \\
\hline EM in total & .083 & .379 \\
External EM & $.232^{*}$ & .012 \\
Introjected EM & -.032 & .731 \\
Identified EM & $-.244^{* *}$ & .008 \\
IM in total & $.249^{* *}$ & .007 \\
IM-Knowledge & $.303^{* *}$ & .001 \\
IM -Accomplishment & $.183^{*}$ & .050 \\
IM-Stimulation & .149 & .109 \\
AM & $-.244^{* *}$ & .007 \\
\hline
\end{tabular}

**. Correlation is significant at the 0.01 level.

*. Correlation is significant at the 0.05 level.

The participants' perceived speaking proficiency showed no statistically significant correlation with the context of the EOP. This finding is not surprising, considering the participants' tepid responses to the context of the EOP (Table 2). In regards to their speaking proficiency, several participants who were advanced in English proficiency also indicated that they were not fully in favor of the EOP. One of the interviewees, identified as an advanced English speaker who had lived in the U.S.A. for nearly three years, commented on the context in a negative manner.

“Well, I don't really get stressed out because of English. But because of the policy, I have more work to do. They (other staff) know that I'm one of the most competent English speakers, and always ask me or other staff who are good at English to do a lot of the English-related work. I feel like I'm doing unnecessary work. Every department has one administrative worker who is good at English as a point of contact, who is practically doing any English-related work, which I don't think is fair in terms of division of work." (P-05)

\section{Discussion}

The findings disclosed two crucial points regarding the influence of the EOP on the participants. First of all, in this EOP context, most of the administrative workers, with higher extrinsic motivation, were found to be less autonomous in L2 learning and tended to self-evaluate their English speaking proficiency to be low. Regarding English learning motivation in an Asian context, L2 researchers have continuously reported higher instrumental, extrinsic motivation than integrative, intrinsic motivation of the learners of English (Ghenghesh, 2010; Kim, 2010; Long, Ming, \& Chen, 2013; Muftah \& Rafik-Galea, 2013; Zhao, 2012). Likewise, most of the participants 
in the current study were more extrinsically motivated to learn English in this workplace. This finding entails a potential problem in L2 achievement. As shown in the studies of Korean EFL learners' L2 motivation, higher autonomy is closely associated with a more internalized level of motivation, i.e., intrinsic motivation, which is often an indicator of better achievements in L2 learning (Kim, 2010; Pae, 2007; Yang, 2009, 2011). Then, the participants in the current study, with increased extrinsic motivation, are less autonomous, and their L2 learning outcome is not expected to be high, despite the university's enforcement of the EOP in the campus. Furthermore, as indicated by some interviewed participants, participants had mixed responses to the policy. On the one hand, they pursued improving English for better positions. On the other hand, given the current work evaluation system and real need of English competence, they found no fundamental reason to develop their English language competence.

Second, the significant correlation between the participants' motivation, especially intrinsic motivation, and their perceived speaking proficiency reveals how motivation may work in EFL speaking. It suggests that perception, rather than a quantified proficiency score, is closely associated with motivation Thus, the more confident the L2 learners are of their speaking abilities, the more intrinsically oriented they tend to be towards English learning. This result supports the claims that some L2 researchers have presented concerning the lack of influence of L2 motivation on achievement and the significant role of perceived L2 competence (Baker \& MacIntyre, 2003; Harley, Cummins, Swain, \& Allen, 1990; Noels, Clément, \& Pelletier, 1999, 2001; Vandergrift, 2005). While motivation does not correlate with actual proficiency levels, their perceived L2 competence was found to be a key factor affecting L2 speakers' level of willingness to communicate. Similarly, the currently study corroborates the role of perceived English competence in the participants' intrinsic motivation. Thus, motivation to speak L2, or to function properly in L2 at the post-tertiary level in the context of the EOP, needs to be examined in terms of how speakers perceive their L2 skills, rather than how much they achieved in an L2 test.

We need to note that despite the continuing significance of English reading under the full execution of the EOP, many participants predicted that speaking would be the most critical skill needed in the future. On the one hand, as an interviewee commented, they projected their anxiety in English speaking to the English-only campus when it would be fully executed in three years' time. In other words, they ranked the skills in terms of what they thought they needed to improve, rather than the skills that would be critical under the full execution of the policy. On the other hand, the participants were less informed of the goals of the EOP. Without a shared understanding of the implementation of the policy, their evaluation of the policy was low, as shown in the descriptive statistics and further indicated by the underrepresentation of some critical foreign language skills like reading.

\section{Conclusion}

Globalization in higher education is frequently noted as an inevitable reality in the 21 st century (Altbach, 2004). Korean society has embraced globalization on a large scale, from industry to education. English competence is now an attribute required in most workplaces. University administrators work in a milieu that is increasingly globalized as a result of the increasing frequency of active academic and business related exchanges. This study examined the policy of English officialization, as recently enforced by one Korean university, in terms of how the policy interplays with the university administrative workers' orientations to learn English.

The findings indicate that researchers and policy makers need to pay more attention to how members of the work community perceive their own foreign language competence under a new foreign language policy. They continuously evaluate and re-evaluate their own English competence under the influence of an immediate, social context, which interplays with their foreign language motivation. It is crucial for policy makers to communicate the goals, functions, and expectations of a foreign language policy with the members of the community. Employees need to be furnished with the specific policy objectives, followed by concrete guidance with regards to how they are supposed to use English in their workplace. They also need to be offered opportunities to improve the necessary English skills, so that the policy can improve administrative performance and efficiency while fostering campus internationalization. The more confident they are of their necessary foreign language skills, the more intrinsically oriented they will be towards English learning, which in turn is closely related with autonomous, successful learning.

Despite the contributions of this study to understanding the interplay between the workplace context of the EOP and motivation, this study is not without limitations. First, since this study investigated a context of the EOP in Korean higher education, the sample size was small, and thus the findings have limited generalizability. The findings also indicate only the degree of influence of motivation and EOP and correlations between them, but not the causation. Therefore, these findings need to be cautiously interpreted, and further research may need to 
address the causation in a systematic manner. Moreover, since this study examined the factors and correlations in terms of the responses of the participants, the findings do not provide information related to objectively evaluated scores of English proficiency. A correlation analysis of the proficiency score data should help policy makers and educators understand and develop specific workplace English learning programs in a more comprehensive and systematic manner so that the needs and requirements of workers are met.

\section{References}

Aju University. (2012). The Ratio of English-medium instruction in selected Korean universities (Unpublished report). Aju University, Seoul, Korea.

Altbach, P. G. (2004). Globalisation and the university: Myths and realities in an unequal world. Tertiary Education \& Management, 10(1), 3-25. http://dx.doi.org/10.1080/13583883.2004.9967114

Altbach, P. G., Reisberg, L., \& Rumbley, L. E. (2009). Trends in global higher education: Tracking an academic revolution. Paper presented at the UNESCO 2009 World Conference on Higher Education, Paris, France.

Baker, S. C., \& MacIntyre, P. D. (2003). The role of gender and immersion in communication and second language orientations. Language Learning, 53(1), 65-96. http://dx.doi.org/10.1111/0023-8333.00224

Block, D. (2004). Globalization and language teaching. ELT Journal, 58(1), 75-77. http://dx.doi.org/10.1093/elt/58.1.75

Chang, Y. (2010). English-medium instruction for subject courses in tertiary education: Reactions from Taiwanese undergraduate students. Taiwan International ESP Journal, 2(1), 55-84.

Cho, D. (2012). English-medium Instruction in the university context of Korea: Tradeoff between teaching outcomes and media-initiated university ranking. The Journal of Asia TEFL, 9(4), 135-163.

Cho, E., Shin, M., Jung, T., Kim, S., \& Park, D. (1998). The study of certification of practical English based on need analysis. Seoul: Korea Institute for Vocational Evaluation.

Choi, S. (2002). The use of the English language in the Korean workplace: A focus on the manufacturing industries (Unpublished doctoral dissertation). University of Southern California, California, U.S.A.

Crystal, D. (2000). Language death. Cambridge: Cambridge University Press. http://dx.doi.org/10.1017/CBO9781139106856

Crystal, D. (2008). Two thousand million? English Today, 24, 3-6. http://dx.doi.org/10.1017/S0266078408000023

Deci, E. L., \& Ryan, R. M. (1985). Intrinsic motivation and self-determination in human behavior. New York, NY: Plenum. http://dx.doi.org/10.1007/978-1-4899-2271-7

Deci, E. L., \& Ryan, R. M. (1995). Human autonomy: The basis for true self-esteem. In M. H. Kernis (Ed.), Efficacy, agency and self-esteem (pp. 31-49). New York: Plenum.

Dörnyei, Z. (1990). Conceptualising motivation in foreign-language learning. Language Learning, 40, 45-78. http://dx.doi.org/10.1111/j.1467-1770.1990.tb00954.x

Dörnyei, Z. (2001). New themes and approaches in second language motivation research. Annual Review of Applied Linguistics, 21, 43-59. http://dx.doi.org/10.1017/S0267190501000034

Edwards, N. (2000). Language for Business: Effective needs assessment, syllabus design and materials preparation in a practical ESP case study. English for Specific Purposes, 19, 191-196.

Evans, S. (2011). Hong Kong English and the professional world. World Englishes, 30(3), 293-316. http://dx.doi.org/10.1111/j.1467-971X.2011.01655.x

Gardner, R. C. (1985). Social psychology and second language learning: The role of attitude and motivation. Baltimore, MD: Edward Arnold.

Ghenghesh, P. (2010). The motivation of L2 learners: Does it decrease with age? English Language Teaching, 3(1), 128-141. http://dx.doi.org/10.5539/elt.v3n1p128

Graddol, D. (1997). The future of English? London: British Council.

Harley, B., Cummins, J., Swain, M., \& Allen, P. (1990). The nature of language proficiency. In B. Harley, P. Allen, J. Cummins, \& M. Swain (Eds.), The development of second language proficiency (pp. 7-25). Cambridge, UK: Cambridge University Press. http://dx.doi.org/10.1017/CBO9781139524568 
Iyengar, S. S., \& Lepper, M. R. (1999). Rethinking the value of choice: A cultural perspective on intrinsic motivation. Journal of Personality and Social Psychology, 76, 349-366. http://dx.doi.org/10.1037/0022-3514.76.3.349

Jensen, H., \& Johannesson, H. (1995). Engineering courses taught in English: An experience from Denmark. European Journal of Engineering Education, 20(1), 19-23. http://dx.doi.org/10.1080/0304379950200103

Johns, A. M., \& Dudley-Evans, T. (1991). English for specific purposes: International in scope, specific in purpose. TESOL Quarterly, 26, 297-314. http://dx.doi.org/10.2307/3587465

Johns, A. M., \& Price-Machado, D. (2001). English for specific purposes: Tailoring courses to student needs and to the outside world. In M. Celce-Murcia (Ed.), Teaching English as a Second or Foreign Language (pp. 43-54). Boston, MA: Heinle \& Heinle Thomson Learning.

Ockey, G. J. (2014). The potential of the L2 group oral to elicit discourse with a mutual contingency pattern and afford equal speaking rights in an ESP context. English for Specific Purposes, 35, 17-29. http://dx.doi.org/10.1016/j.esp.2013.11.003

Kachru, B. (Ed.). (1992). The other tongue. Urbana and Champaign, IL: University of Illinois Press.

Kahng, Y. (1999). Immersion education in Southeast Asia. English Language \& Literature Teaching, 5, 79-101.

Kim, J. (2010). L2 Learner's perspectives of how personal and instructional factors influence achievement in online EFL learning environment. English Language \& Literature Teaching, 16(4), 39-69.

Kormos, J., Kiddle, T., \& Csizér, K. (2011). Systems of goals, attitudes, and self-related beliefs in second language learning motivation. Applied Linguistics, 32(5), 495-516. http://dx.doi.org/10.1093/applin/amr019

Kozaki, Y., \& Ross, S. J. (2011). Contextual dynamics in foreign language learning motivation. Language Learning, 61(4), 1328-1354. http://dx.doi.org/10.1111/j.1467-9922.2011.00638.x

Littlewood, W. (1996). "Autonomy": An anatomy and a framework. System, 24, 427-435. http://dx.doi.org/10.1016/S0346-251X(96)00039-5

Littlewood, W. (1999). Defining and developing autonomy in East Asian contexts. Applied Linguistics, 20, 71-94. http://dx.doi.org/10.1093/applin/20.1.71

Long, C., Ming, Z., \& Chen, L. (2013). The study of student motivation on English learning in junior middle school-A case study of No.5 Middle School in Geiju. English Language Teaching, 6(9), 136-145. http://dx.doi.org/10.5539/elt.v6n9p136

MacIntyre, P. D., \& Legatto, J. J. (2011). A Dynamic system approach to willingness to communicate: Developing an idiodynamic method to capture rapidly changing affect. Applied Linguistics, 32(2), 149-171. http://dx.doi.org/10.1093/applin/amq037

Manakul, W. (2007). Role of English in internationalization of higher education: The case of the Graduate School of Engineering, Hokkaido University. Higher Education and Lifelong Learning, 15, 155-162.

Manh, L. D. (2012). English as a medium of instruction at tertiary education system in Vietnam. The Journal of Asia TEFL, 9(2), 97-122.

Muftah, M., \& Rafik-Galea, S. (2013). Language learning motivation among Malaysian pre-university students. English Language Teaching, 6(3), 92-103. http://dx.doi.org/10.5539/elt.v6n3p92

Murray, G. (2007). Classroom motivation of Korean EFL students from the perspective of self-determination theory. English Teaching, 62(4), 391-409.

Noels, K. A., Clément, R., \& Pelletier, L. G. (1999). Perceptions of teachers' communicative style and students' intrinsic and extrinsic motivation. Modern Language Journal, 83, 23-34. http://dx.doi.org/10.1111/0026-7902.00003

Noels, K. A., Clément, R., \& Pelletier, L. G. (2001). Intrinsic, extrinsic, and integrative orientations of French Canadian learners of English. Canadian Modern Language Review, 57, 424-440. http://dx.doi.org/10.3138/cmlr.57.3.424

Noels, K. A., Pelletier, L. G., \& Vallerand, R. (2000). Why are you learning a second language? Motivation orientations and self-determination theory. Language Learning, 50(1), 57-85. http://dx.doi.org/10.1111/0023-8333.00111 
Pae, T. (2007). Why do they want to learn English? A self-determination theory perspective. English Teaching, $62,177-191$.

Park, H., \& Jung, B. (2006). The use of English in the Korean workplace: A case study. The Journal of Linguistic Science, 37, 113-138.

Rivers, D. J. (2011). Strategies and struggles in the ELT classroom: Language policy, learner autonomy, and innovative practice. Language Awareness, 20(1), 31-43. http://dx.doi.org/10.1080/09658416.2010.537343

Swales, J. (1987). Utilizing the literatures in teaching the research paper. TESOL Quarterly, 21, 41-68. http://dx.doi.org/10.2307/3586354

Tsuneyoshi, R. (2005). The dilemmas and possibilities of study abroad programs using English. Journal of Research in International Education, 4(1), 65-86. http://dx.doi.org/10.1177/1475240905050291

Vallerand, R. J., Pelletier, L. G., Blais, M. R., Brière, N. M., Senécal, C., \& Vallières, E. F. (1992). The academic motivational scale: A measure of intrinsic, extrinsic, and amotivation in education. Educational and Psychological Measurement, 52, 1003-1017. http://dx.doi.org/10.1177/0013164492052004025

Vallerand, R. J., Pelletier, L. G., Blais, M. R., Brière, N. M., Senécal, C., \& Vallières, E. F. (1993). Assessment of intrinsic, extrinsic and amotivation in education: Evidence on the concurrent and construct validity of the academic motivation scale. Educational and Psychological Measurement, 53, 159-172. http://dx.doi.org/10.1177/0013164493053001018

Vallerand, R. J. (1997). Toward a hierarchical model of intrinsic and extrinsic motivation. In M. P. Zanna (Ed.), Advances in Experimental Social Psychology (pp. 271-360). San Diego, CA: Academic Press.

Vandergrift, L. (2003). Orchestrating strategy use: Toward a model of the skilled second language listener. Language Learning, 53(3), 463-496. http://dx.doi.org/10.1111/1467-9922.00232

Vandergrift, L. (2005). Relationships among motivation orientations, metacognitive awareness and proficiency in L2 Listening. Applied Linguistics, 26(1), 70-89. http://dx.doi.org/10.1093/applin/amh039

Yang, E. (2009). Korean EFL learners' reading motivation and their L2 reading behavior. English Language \& Literature Teaching, 15(4), 217-235.

Yang, E. (2011). Korean college students' English learning motivation and listening proficiency. English Language \& Literature Teaching, 17(2), 93-114.

Zhao, L. (2012). Investigation into motivation types and influences on motivation: The case of Chinese non-English majors. English Language Teaching, 5(3), 100-122. http://dx.doi.org/10.5539/elt.v5n3p100

\section{Appendix}

Questionnaire items

1) How long have you worked for the university?

2) Have you ever lived in an English-speaking country? If yes, please indicate the length of the time of the stay.

3) Do you a score of any standardized English, such as TOEIC? If yes, please indicate the score.

4) Which of the following descriptions fits your English speaking proficiency best?

( ) I am able to understand and read English text, but hardly speak English

( ) I am able to participate in a short dialog, but have difficulty with managing discussions and negotiations.

( ) I hardly have difficulty with English communication

5) Indicate the number in each of the following according to the degree of importance (1: most important, 4 : least important)

Under the EOP in full execution, which English skill do you think would be most important?

Listening ( ) Reading ( ) Speaking ( ) Writing ( )

6) English officialization policy (EOP) affects my work environment and performance at the present and will continuously do so for the next 1-2 years.

7) I think that the EOP has more to do with instructors and students than to the staff members.

8) I feel like to study English more because of the EOP. 
9) English competence is important for promotion and a prestigious position later on.

10) English competence is important for earning more money later on.

11) I can show that I am a good global citizen by speaking English well.

12) I (will) study English because I would feel ashamed if I couldn't speak to my coworkers or native English speakers in English.

13) I think English competence is important for my personal development.

14) I choose to be the kind of person who can speak English at work, which is why I (will) study English.

15) I (will) study English speaking for the feeling of acquiring knowledge about the English-speaking community and their way of life.

16) I (will) study English for the satisfied feeling I get in finding out new things.

17) I (will) study English for the enjoyment I experience when I understand a difficult idea in English.

18) I (will) study English for the enjoyment that I experience when I am accomplishing difficult exercises in dialogs.

19) I feel like to study English more for the "high" feeling that I experience while speaking English.

20) I feel like to study English more for the pleasure I get from hearing English spoken by English-speaking people.

21) I really don't know why I study English.

22) I feel like I am wasting my time in studying English.

\section{Copyrights}

Copyright for this article is retained by the author(s), with first publication rights granted to the journal.

This is an open-access article distributed under the terms and conditions of the Creative Commons Attribution license (http://creativecommons.org/licenses/by/3.0/). 